\title{
Educação Financeira no Ensino Médio: uma análise de atividades didáticas relacionadas a séries periódicas uniformes sob o ponto de vista da Educação Matemática Crítica
}

\author{
Financial Education in High School: an analysis of didactic activities \\ related to uniform periodic series from the point of view of Critical \\ Mathematics Education
}

Andrei Luís Berres Hartmann*

ORCID iD 0000-0001-5240-7038

Rita de Cássia Pistóia Mariani ${ }^{* *}$

ORCID iD 0000-0002-8202-8351

Marcus Vinicius Maltempi ${ }^{* * *}$

ORCID iD 0000-0001-5201-0348

\begin{abstract}
Resumo
O objetivo deste estudo foi identificar e analisar atividades didáticas desenvolvidas no Ensino Médio que podem envolver tomada de decisão em situações econômico-financeiras relacionadas a séries periódicas uniformes. Perspectivas relacionadas à Educação Financeira, Educação Financeira Escolar e Educação Matemática Crítica forneceram sustentação teórica ao estudo. Por tratar-se de uma pesquisa qualitativa, em que foi realizado um levantamento bibliográfico a partir do Catálogo de Teses e Dissertações da Capes, a produção de dados também considerou princípios da análise de conteúdo. Nessa plataforma foi possível identificar 333 produções de mestrado ou doutorado, tendo como palavra-chave "Educação Financeira". Após restringir os dados, foram selecionadas seis atividades didáticas de pesquisas realizadas na modalidade profissional e que desenvolveram essas questões com estudantes do Ensino Médio. Para a análise das atividades foram sistematizados três descritores, a partir dos estudos de Muniz (2016) e Rocha (2017): Interpretação do Contexto (D1), Tomada de Decisão (D2) e Argumento na Tomada de Decisão (D3). Pelas atividades consideradas, pode-se destacar que as pesquisas permitiram que seus participantes refletissem sobre situações cotidianas (identificação de D1 em cinco atividades), porém as questões não admitiram a tomada de decisão a partir dos três argumentos considerados: sociocultural (SC), econômicofinanceiro (E-F) e comportamental (C). Para tanto, propõe-se que o estudo de progressões geométricas, fortemente relacionado a séries periódicas uniformes, seja realizado pautado na Educação Financeira e na Educação Matemática Crítica, ainda no Ensino Médio.

Palavras-chave: Educação Financeira. Tomada de Decisão. Progressão Geométrica. Educação Matemática

\footnotetext{
* Licenciado em Matemática pela Universidade Federal de Santa Maria (UFSM). Mestrando em Educação Matemática pela Universidade Estadual Paulista (UNESP), Rio Claro, São Paulo, Brasil. E-mail: andreiluis_spm@hotmail.com.

** Doutora em Educação Matemática pela Pontifícia Universidade Católica de São Paulo (PUCSP). Docente do Departamento de Matemática da Universidade Federal de Santa Maria (UFSM), Santa Maria, Rio Grande do Sul, Brasil.E-mail: rcpmariani@yahoo.com.br.

*** Doutor em Engenharia Elétrica e de Computação pela Universidade Estadual de Campinas (Unicamp). Livre Docente em Educação Matemática e Professor da Universidade Estadual Paulista (UNESP), Rio Claro, São Paulo, Brasil. E-mail: marcus.maltempi@unesp.br.
} 
Crítica. Levantamento Bibliográfico.

\begin{abstract}
The objective of this study was to identify and analyze didactic activities developed in High School which may involve decision making in economic-financial situations related to uniform periodic series. Perspectives related to Financial Education, School Financial Education, and Critical Mathematical Education provided theoretical support for the study. As this is a qualitative research in which a bibliographic survey was carried out based on Capes' Theses and Dissertations Catalog, data production also considered the principles of content analysis. Through this platform it was possible to identify 333 master's or doctorate productions, using the keyword "Financial Education". After data were restricted, we selected six didactic research activities carried out in the professional modality and which developed these issues with high school students. For the analysis of activities, three descriptors were systematized, based on the studies by Muniz (2016) and Rocha (2017): Context Interpretation (D1), Decision Making (D2), and Argument in Decision Making (D3). For the activities considered, it can be highlighted that the research allowed its participants to reflect on everyday situations (identification of D1 in five activities), but the issues did not admit decision making based on the three arguments considered: sociocultural (SC), economic-financial (EF), and behavioral (C). Therefore, it is proposed that the study of geometric progressions, strongly related to uniform periodic series, be conducted based on Financial Education and Critical Mathematical Education, still in High School.
\end{abstract}

Keywords: Financial Education. Decision Making. Geometric Progression. Critical Mathematics Education. Bibliographic Survey.

\title{
1 Considerações iniciais
}

A Educação Financeira ganhou maior ênfase em estudos e documentos legislativos em âmbito educacional a partir de pesquisas e direcionamentos sobre o assunto promovidos e financiados pela Organização para a Cooperação e Desenvolvimento Econômico (OCDE) ${ }^{1}$, (OCDE, 2005). Aos poucos, essa temática apresentou-se como uma maneira de oportunizar discussões sobre aspectos relacionados ao cotidiano dos indivíduos, fazendo com que pessoas passassem a refletir sobre situações de compra, uso do dinheiro e, principalmente, as consequências do consumo.

Por meio da proposta da OCDE e outras considerações, Silva e Powell (2013; 2015), ao se preocuparem com a efetivação de um projeto de inserção da Educação Financeira no ambiente escolar, utilizaram a expressão Educação Financeira Escolar, destacando o intuito principal de educar financeiramente os estudantes nas escolas e não de formar consumidores. Assim, a Educação Financeira Escolar:

[...] constitui-se de um conjunto de informações através do qual os estudantes são introduzidos no universo do dinheiro e estimulados a produzir uma compreensão sobre finanças e economia, através de um processo de ensino, que os torne aptos a analisar, fazer julgamentos fundamentados, tomar decisões e ter posições críticas sobre questões financeiras que envolvam sua vida pessoal, familiar e da sociedade em que vivem (SILVA; POWELL, 2013, p. 12-13).

\footnotetext{
${ }^{1}$ A OCDE foi fundada em 1961 visando o estímulo do progresso econômico e comércio mundial, principalmente para países de alta economia.
} 
Ao tratar sobre o estudo da Educação Financeira no ambiente escolar, uma possibilidade que emerge é sua abordagem por meio de atividades didáticas de Matemática na sala de aula, aliando tópicos de Matemática escolar inclusos no currículo, com situações que oportunizem reflexões por intermédio de argumentos matemáticos e não-matemáticos, como valores familiares, crenças, emoções e heurísticas. Nessa perspectiva, a Base Nacional Comum Curricular (BNCC), (BRASIL, 2018), aponta a necessidade do tratamento contextualizado de temas importantes na contemporaneidade, dentre eles a Educação Financeira.

Muniz (2016) ponderou sobre o processo de tomada de decisão mediante tarefas inseridas em Ambientes de Educação Financeira Escolar. Para tanto, considerou perspectivas da Economia Tradicional e da Psicologia Econômica "por representarem os dois principais movimentos sobre tomada de decisão do século XX” (MUNIZ, 2016, p. 112).

No campo da Educação Matemática, a tomada de decisão está presente em apontamentos de Skovsmose $(2000 ; 2001 ; 2007$; 2014) relacionados à Educação Matemática Crítica, que considera a importância de se discutir Matemática a partir de perspectivas sociais, políticas e econômicas. O autor dispõe que, na Matemática em ação, não se pode "operar com a informação, que serviria como base para a tomada de decisões sem o suporte da Matemática. A Matemática faz parte de uma tomada real de decisões" (SKOVSMOSE, 2007, p. 118), além de aspectos relacionados à economia serem importantes para uma análise e compreensão crítica de questões políticas e sociais.

Estudos relacionados à Educação Financeira e tomada de decisão indicam a necessidade e a importância de se discutir esses assuntos no ambiente escolar. Em Baroni et al. (2019, p. 177), foi apresentada uma atividade que possibilita auxiliar a escolha de um financiamento de automóvel, apontando "que o estudante pode ser engajado em reflexões posteriores à tomada de decisão". Ademais, segundo Muniz e Jurkiewicz (2016), embora sejam realizadas pesquisas sobre situações financeiras no ambiente escolar, muitas vezes essas não enfatizam o processo de tomada de decisão.

Na pesquisa desenvolvida por Hartmann et al. (2019), ao proporem um jogo com foco na tomada de decisão, os autores destacaram que os estudantes participantes explicitaram riscos que o consumo exagerado pode provocar, além de compreenderem situações financeiras, bem como refletir sobre elas. Cunha e Laudares (2017) afirmam que atividades sobre Educação Financeira, a partir de conceitos de Matemática Financeira, possibilitaram discussões de questões econômicas, sociais e políticas no ambiente escolar, promovendo uma melhora na postura reflexiva dos estudantes.

Diante do exposto, a compreensão sobre Educação Financeira adotada pelos autores 
deste artigo vai ao encontro do proposto por Silva e Powell (2013), considerando o ambiente escolar de fundamental importância para a discussão de aspectos relacionados à Educação Financeira, sobretudo, oportunizando escolhas conscientes e críticas.

O estudo de Hartmann (2019) objetivou identificar e analisar aspectos de tomada de decisão em situações econômico-financeiras que envolvem séries periódicas uniformes. A partir de seu aprofundamento e ampliação das discussões, neste artigo objetiva-se identificar e analisar atividades didáticas desenvolvidas no Ensino Médio, as quais podem envolver tomada de decisão em situações econômico-financeiras relacionadas a séries periódicas uniformes, no âmbito da Educação Financeira e Educação Matemática Crítica.

A escolha por atividades didáticas sobre séries periódicas uniformes, também denominadas como "rendas certas ou anuidades", ocorreu pelo fato desse conceito estar relacionado ao de progressões geométricas, conteúdo abordado no Ensino Médio. Em séries periódicas uniformes, consideram-se recebimentos, prestações ou desembolsos, de mesmo valor, em parcelas de tempo iguais.

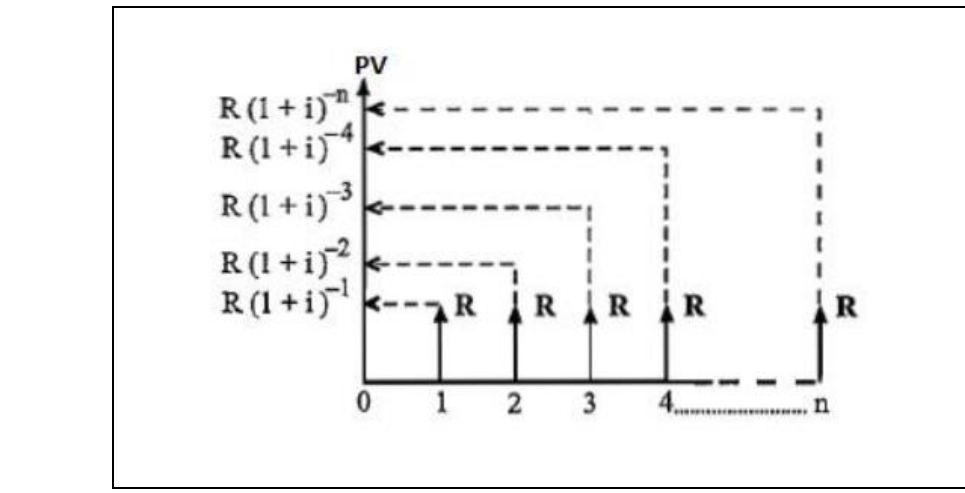

Figura 1 - Representação de valor presente de séries periódicas uniformes Fonte: Hartmann (2019, p. 27).

Ao ser estudada a soma dos valores das rendas a uma taxa de juros (i), tem-se o somatório de termos de uma progressão geométrica, de razão $1+\mathrm{i}$. Ressalta-se que as anuidades podem ser de capitalização ou amortização, porém, com maior frequência, relacionam-se com situações de amortização na aquisição de bens e serviços, como, por exemplo: "adquira hoje em 10 parcelas com entrada", ou seja, 1 + 9 (série antecipada); "compre e pague em 12 vezes, sem entrada" (série postecipada); ou, ainda, "compre hoje em 24 vezes - sem juros - e comece a pagar somente daqui a três meses" (série diferida). 


\section{Algumas ideias de Educação Financeira e Educação Matemática Crítica}

Em 2005, a OCDE definiu² a Educação Financeira no documento "Recomendação sobre princípios e boas práticas para a educação e conscientização financeira”. Dentre as ações públicas propostas por essa organização, para a ocorrência de boas práticas de educação e conscientização financeira, consta que a Educação Financeira deveria ser iniciada nas escolas.

No Brasil, implementou-se a Estratégia Nacional de Educação Financeira (ENEF), (BRASIL, 2010), visando a tomada de decisão consciente por parte dos consumidores brasileiros, dentre outras finalidades. Essa estratégia foi responsável pela criação do Programa Educação Financeira nas Escolas, para que a temática fosse abordada em diferentes áreas de conhecimento nos estabelecimentos de ensino. Segundo Hofmann e Moro (2013, p. 48) esteve ${ }^{3}$ "previsto na ENEF, além de ações destinadas à educação de adultos, um conjunto de medidas voltadas especificamente para a educação financeira nas escolas".

Nesse sentido, Silva e Powell (2013), ao discutirem sobre a Educação Financeira Escolar, indicam possibilidades de desenvolvimento de um currículo para escolas públicas da Educação Básica. Para tal, propõem uma Educação Financeira "cuja análise de situações problemas que os estudantes vivenciarão tenha fundamentação matemática como auxiliar na tomada de decisões" (SILVA; POWELL, 2013, p. 12)

Ademais, o currículo deveria ser organizado por quatro eixos norteadores, sendo discutidos ao longo de toda etapa escolar, quais sejam: noções básicas de finanças e economia; finança pessoal e familiar; as oportunidades, os riscos e as armadilhas na gestão do dinheiro numa sociedade de consumo; as dimensões sociais, econômicas, políticas, culturais e psicológicas que envolvem a Educação Financeira (SILVA; POWELL, 2013).

Muniz (2016), por meio de seu estudo desenvolvendo atividades no âmbito da Educação Financeira Escolar, apontou a importância da Educação Financeira na construção da cidadania, além de considerar que Ambientes de Educação Financeira Escolar possam ser formados em diversos espaços, como em aulas, pesquisas acadêmicas, seminários, palestras e formação de professores. Ademais, o estudioso mencionado indicou cinco aspectos não-matemáticos que podem ser considerados na tomada de decisão em situações econômico-financeiras: culturais,

\footnotetext{
${ }^{2}$ Em sua versão original, Educação Financeira corresponde a: "the process by which financial consumers/investors improve their understanding of financial products, concepts and risks and, through information, instruction and/or objective advice, develop the skills and confidence to become more aware of financial risks and opportunities, to make informed choices, to know where to go for help, and to take other effective actions to improve their financial well-being" (OCDE, 2005, p. 4).

${ }^{3} \mathrm{O}_{\text {decreto }}{ }^{\circ} 10.393$, de 9 de junho de 2020, instituiu a nova ENEF e o Fórum Brasileiro de Educação Financeira (FBEF).
} 
financeiros, econômicos, sociais e comportamentais.

A partir desses aspectos, investigando o processo de tomada de decisão com licenciandos em Matemática por meio de situações econômico-financeiras, Rocha (2017) sistematizou três categorias emergentes em argumentos referentes à tomada de decisão: sociocultural, econômico-financeira e comportamental. Para a autora:

\begin{abstract}
os aspectos que podem estar envolvidos na tomada de decisão dos participantes da pesquisa, podem ser relacionados aos hábitos, crenças, valores familiares e da sociedade - sociocultural (SC); os aspectos abarcados na aquisição, investimento, uso e distribuição do dinheiro ou também interligado à economia - econômico-financeiro (E-F) e a aspectos envolvendo emoção, paciência, a também às heurísticas comportamental (C) (ROCHA, 2017, p. 71).
\end{abstract}

Em sua dissertação, Rocha (2017) explorou tarefas sobre séries periódicas uniformes para analisar a tomada de decisão de licenciandos em Matemática. Segundo a autora, esse tipo de atividade, além de proporcionar algumas reflexões e deliberações, despertou diversas discussões sobre consumo. Mediante a pesquisa de Rocha (2017), foi possível identificar que a tomada de decisão em situações econômico-financeiras pode ser um fundamental objetivo da Educação Financeira, principalmente quando inserida no processo de ensino. Além disso, é possível evidenciar a relevância do estudo de séries periódicas uniformes presentes em situações de compra e investimentos atuais.

A tomada de decisão, proporcionada por atividades didáticas de Educação Financeira, permite oportunizar a criticidade, principalmente pelo diálogo entre alunos e professores, de acordo com as proposições da Educação Matemática Crítica. Para Skovsmose (2001, p. 87), a educação deve preparar estudantes para sua "futura participação nos processos de trabalho na sociedade, ampliando, também, para os aspectos da vida social, cultural e política”.

Outrossim, de acordo com Skovsmose (2014), uma das ocupações da Educação Matemática é, também, a preparação para o consumo, permitindo reflexões sobre a responsabilidade social quando torna isso possível. Entende-se que a Educação Financeira vai ao encontro dessa assertiva e, principalmente, ao considerar conteúdos matemáticos, favorece o desenvolvimento da matemacia, termo adotado pelo teórico para se referir a uma competência que possibilita a compreensão de situações sociais e políticas pela Matemática.

\footnotetext{
Se adotássemos uma concepção mais ampla de consumo, que incluísse as práticas de ler e trabalhar informações expressas em números, então uma matemacia do consumir poderia ser pensada em termos de uma cidadania funcional, isto é, as pessoas estariam aptas a receber informações de diversas fontes constituídas, e proceder da maneira esperada" (SKOVSMOSE, 2014, p. 111).
}

Nesse âmbito, torna-se necessário mencionar a importância do desenvolvimento de cenários de investigação, nos quais os estudantes são convidados ao envolvimento de processos 
de exploração e argumentação justificada (SKOVSMOSE, 2000). Compreende-se a necessidade da abordagem da Educação Financeira com referências à vida real dos estudantes (SKOVSMOSE, 2000; 2014), para que maiores reflexões sejam oportunizadas, possibilitando questionamentos, investigações, levantamento de hipóteses e a argumentação.

Diante do exposto, compreende-se que o principal espaço para a discussão de assuntos relacionados à Educação Financeira é a Educação Básica, oportunizando um ambiente de reflexão, por meio da realização de atividades amparadas na Educação Matemática Crítica e que podem levar estudantes à tomada de decisão, englobando aspectos matemáticos e nãomatemáticos, como proposto fortemente nas pesquisas de Muniz (2016) e Rocha (2017).

\section{Procedimentos metodológicos}

Neste trabalho, para cumprir com o objetivo proposto, a preocupação está centrada com a significância, ideias, entendimentos e interações presentes nos dados e nas produções nacionais, caracterizando o estudo como uma abordagem qualitativa de pesquisa (YIN, 2016; BORBA; ARAÚJO, 2004). Nessa perspectiva qualitativa, foi utilizado o levantamento bibliográfico para a busca de pesquisas de mestrado e doutorado sobre Educação Financeira, a partir das concepções apontadas por Fiorentini e Lorenzato (2006).

A produção de dados foi norteada pelos princípios da análise de conteúdo, proposta por Bardin (2016), tomando como base os três momentos: pré-análise; exploração do material; e tratamento dos resultados e interpretação. A pré-análise foi caracterizada pela busca e seleção de produções nacionais. Por sua vez, a exploração de material consistiu no refinamento das pesquisas encontradas, selecionando-se aquelas que apresentaram o termo "Educação Financeira" no título e que foram realizadas em programas de pós-graduação na modalidade profissional, além da busca e exclusão de atividades presentes nas produções idealizadas com estudantes do Ensino Médio e que continham, ou não, dados suficientes para subsidiar a análise. Por fim, o tratamento dos resultados e interpretação compreende a síntese das atividades didáticas e sua categorização, segundo os descritores sistematizados a priori a partir de entendimentos sobre Educação Financeira e Educação Matemática Crítica (vide seção 4).

Por meio dos argumentos supracitados, utilizando-se do Catálogo de Teses e Dissertações da Coordenação de Aperfeiçoamento de Pessoal de Nível Superior (Capes) e do termo "Educação Financeira", foi possível identificar 333 pesquisas, durante os meses de maio a setembro de 2019. Dispondo dos próprios recursos do banco de dados, verificou-se que desse total, 139 produções se realizaram nas três áreas de conhecimento adotadas na pesquisa: 
Educação (23), Ensino (31) e Ensino de Ciências e Matemática (85). Destaca-se que 58 trabalhos foram classificados na área de concentração Educação Matemática.

A partir do acervo dessas 139 pesquisas, selecionou-se aquelas que apresentavam o termo "Educação Financeira" no título, restringindo o estudo a 86 trabalhos. Posteriormente, com o auxílio da própria plataforma de busca, identificou-se 51 pesquisas realizadas em programas na modalidade profissional. Tal restrição foi adotada pela crescência desses programas no Brasil, sendo apontado por Araújo-Jorge, Sovierzoski e Borba (2017) que 56\% da área de Ensino é composta por essa modalidade, além de Cirani, Campanario e Silva (2015) revelarem aumento de $1.971 \%$ em matrículas de mestrado profissional, entre 1999 e 2011.

Como recorte dos dados, analisou-se pesquisas que idealizaram atividades no Ensino Médio, por ser o nível escolar em que o conceito de progressão geométrica é abordado,o qual tem forte relação com séries periódicas uniformes. Assim, foram consideradas 35 atividades relacionadas aos objetivos da pesquisa, em 12 trabalhos. O Quadro 1, na sequência, apresenta essas 12 produções, distribuídas por instituição de ensino superior (IES), título, autor e ano.

\begin{tabular}{|c|c|c|}
\hline IES & TÍTULO & AUTOR (ANO) \\
\hline $\begin{array}{l}\text { Pontifícia Universidade } \\
\text { Católica de Minas Gerais }\end{array}$ & $\begin{array}{c}\text { Educação Financeira: uma perspectiva da disciplina } \\
\text { Matemática no Ensino Médio pela Resolução de Problemas }\end{array}$ & $\begin{array}{l}\text { Clístenes L. da } \\
\text { Cunha (2014) }\end{array}$ \\
\hline $\begin{array}{l}\text { Universidade de } \\
\text { Araraquara }\end{array}$ & $\begin{array}{c}\text { Educação financeira: uma proposta interdisciplinar de } \\
\text { trabalho com o ensino médio }\end{array}$ & $\begin{array}{c}\text { Antônio R. } \\
\text { Trevisan (2018) }\end{array}$ \\
\hline \multirow{3}{*}{$\begin{array}{l}\text { Universidade Federal de } \\
\text { Juiz de Fora }\end{array}$} & $\begin{array}{c}\text { Investigando como a educação financeira crítica pode } \\
\text { contribuir para tomada de decisões de consumo de jovens- } \\
\text { indivíduos-consumidores (JIC'S) }\end{array}$ & $\begin{array}{c}\text { André B. } \\
\text { Campos (2013) }\end{array}$ \\
\hline & $\begin{array}{l}\text { Educação financeira escolar: os riscos e as armadilhas } \\
\text { presentes no comércio, na sociedade de consumidores }\end{array}$ & $\begin{array}{l}\text { Vivian H. B. da } \\
\text { C. Silva (2017) }\end{array}$ \\
\hline & $\begin{array}{l}\text { Produção e implementação de um simulador financeiro } \\
\text { como aporte a tarefas destinadas ao ensino de Educação } \\
\text { Financeira Escolar }\end{array}$ & $\begin{array}{l}\text { Alex M. Leite } \\
\quad(2018)\end{array}$ \\
\hline \multirow{2}{*}{$\begin{array}{l}\text { Universidade Federal de } \\
\text { Ouro Preto }\end{array}$} & $\begin{array}{c}\text { Resolução de problemas e simulações: investigando } \\
\text { potencialidades e limites de uma proposta de Educação } \\
\text { Financeira para alunos do Ensino Médio de uma escola da } \\
\text { rede privada de Belo Horizonte (MG) }\end{array}$ & $\begin{array}{l}\text { Luciene de } \\
\text { Sousa (2012) }\end{array}$ \\
\hline & $\begin{array}{l}\text { Investigando uma sequência didática sobre juros compostos } \\
\text { para a formação em educação financeira de alunos do ensino } \\
\text { médio }\end{array}$ & $\begin{array}{l}\text { Aline A. S. L. } \\
\text { Sodré (2018) }\end{array}$ \\
\hline $\begin{array}{l}\text { Universidade Federal do } \\
\text { Rio Grande do Sul }\end{array}$ & $\begin{array}{c}\text { Investigação sobre as contribuições da Matemática para o } \\
\text { desenvolvimento da Educação Financeira na escola }\end{array}$ & $\begin{array}{c}\text { Samuel R. } \\
\text { Raschen (2016) }\end{array}$ \\
\hline $\begin{array}{l}\text { Universidade de Passo } \\
\text { Fundo }\end{array}$ & $\begin{array}{c}\text { Educação financeira no ensino médio: uma análise a partir } \\
\text { da aprendizagem significativa de David Ausubel }\end{array}$ & $\begin{array}{l}\text { Laercio Villa } \\
(2017)\end{array}$ \\
\hline $\begin{array}{l}\text { Univerdidade do Vale do } \\
\text { Taquari }\end{array}$ & $\begin{array}{l}\text { Educação financeira na sala de aula: uma proposta } \\
\text { metodológica para o ensino da matemática no ensino médio }\end{array}$ & $\begin{array}{l}\text { Patrícia S. de } \\
\text { Argôlo (2018) }\end{array}$ \\
\hline $\begin{array}{l}\text { Universidade Regional } \\
\text { Integrada do Alto Uruguai } \\
\text { e das Missões }\end{array}$ & $\begin{array}{c}\text { E-book Interativo: um olhar para a Educação Financeira na } \\
\text { educação básica }\end{array}$ & $\begin{array}{l}\text { Marisa do C. P. } \\
\text { da Silva (2017) }\end{array}$ \\
\hline $\begin{array}{l}\text { Universidade Tecnológica } \\
\text { Federal do Paraná }\end{array}$ & Tarefas para uma educação financeira: um estudo & $\begin{array}{c}\text { Daniela } \\
\text { Harmuch (2017) }\end{array}$ \\
\hline
\end{tabular}

Quadro 1 - Síntese das produções analisadas

Fonte: Os autores (2021) 
Mediante a apreciação das pesquisas e das atividades identificadas, ainda na segunda fase da análise de conteúdo, foram excluídas deste estudo aquelas que não haviam sido implementadas ou que continham raras informações sobre seu desenvolvimento e análise. Por exemplo, em Trevisan (2018) foi possível localizar cinco atividades, em que se apresenta uma proposta de abordagem da Educação Financeira de maneira interdisciplinar, mas tais questões não foram desenvolvidas no ambiente escolar. Nas pesquisas de Raschen (2016), Harmuch (2017) e Silva (2017a), foram localizadas, respectivamente, cinco, uma e uma atividade, todavia em todas constam poucos detalhamentos sobre o desenvolvimento das questões e questionamentos produzidos pelos estudantes, o que contribuiu para a exclusão.

A análise de dados da pesquisa de Cunha (2014) buscou compreender potencialidades das questões, a partir de cinco tipos de erros: erro de incompreensão do texto introdutório; erro de incompreensão da situação-problema; erro do emprego de fórmulas/conceitos; erro operacional no emprego de fórmulas/conceitos; e erro na interpretação crítica na conclusão. Embora tenham sido observadas sete atividades relacionadas com os objetivos deste artigo, essas estão apresentadas no produto educacional da dissertação de Cunha (2014), o que dificultou a abordagem dessas atividades na análise, aqui proposta, pela falta de comentários e reflexões do estudo referido.

Semelhante ao observado em Cunha (2014), as três atividades localizadas na pesquisa de Villa (2017) estão apresentadas no produto educacional e não são analisadas isoladas no corpo do texto. Por fim, identificou-se que em Campos (2013, p. 126), uma atividade foi utilizada para apoiar outra situação-problema, não idealizada pelos participantes da pesquisa.

Diante do exposto, este estudo versou sobre doze (12) atividades didáticas de seis pesquisas: três em Sousa (2012); três em Campos (2013); duas em Leite (2018); duas em Sodré (2018); uma em Argôlo (2018); e uma em Silva (2017b). Com o intuito de explicitar minuciosamente a produção de dados e exemplificar análise das demais questões, selecionouse uma atividade de cada produção para ser abordada neste artigo.

\section{Análise das atividades didáticas, à luz da Educação Matemática Crítica, por meio dos descritores}

Com o intuito de analisar as atividades didáticas identificadas nas produções nacionais, por meio da revisão de literatura e, principalmente, os estudos realizados por Muniz (2016) e Rocha (2017), foram sistematizados três descritores pelos autores deste artigo, a saber:

D1 - Interpretação do Contexto: descritor relacionado com a forma como a questão é 
anunciada, de modo a permitir aos indivíduos a identificação de um contexto coeso e coerente, mediante uma situação financeira que incorpore elementos matemáticos e não-matemáticos. Esse fato vai ao encontro da Educação Matemática Crítica, ao considerar que as atividades abordadas devam ser relevantes para os estudantes, estando aliadas aos seus interesses, sobretudo por proporcionar reflexões relacionadas à vida real (SKOVSMOSE, 2014).

D2 - Tomada de Decisão: engloba os argumentos presentes na resolução da atividade didática, os quais podem levar os sujeitos à tomada de decisão. Assim, esse descritor está voltado a analisar se a atividade permite que os indivíduos possam fazer escolhas e expressar diferentes perspectivas de ideias, indo além de encontrar apenas uma resposta exata a um problema matemático, podendo considerar fatores humanos nesse processo. Sendo a tomada de decisão "uma nova cena onde matemática e poder interagem, e um aspecto importante dessa interação é a eliminação do que poderia ser chamado fator humano. Um ser humano pode sentirse pesaroso ou irritado e isso pode influenciar sua decisão" (SKOVSMOSE, 2007, p. 132).

D3 - Argumento na Tomada de Decisão: refere-se aos aspectos matemáticos e nãomatemáticos que podem ser considerados na tomada de decisão assumindo a proposta de Rocha (2017): sociocultural (SC), econômico-financeiro (E-F) e comportamental (C), para tanto, considera-se os argumentos presentes na resolução da atividade didática.

Nesta seção, a fim de expor e organizar a análise, em cada quadro são apresentados: a atividade didática extraída das pesquisas analisadas; excertos das produções elaboradas que auxiliaram na categorização; e os descritores enquadrados em cada caso. Inicialmente, é apresentada a análise da atividade (Quadro 2) da pesquisa de Sousa (2012). Ao objetivar avaliar uma proposta de um conjunto de atividades sobre Educação Financeira, a estudiosa desenvolveu um trabalho com estudantes de $1^{\circ}$ e $2^{\circ}$ ano de Ensino Médio numa escola de rede privada de Belo Horizonte. Dentre os resultados, a autora destacou que os sujeitos mudaram sua postura, com maior participação e envolvimento e, assim, obtiveram conhecimentos e uma nova linguagem sobre finanças.

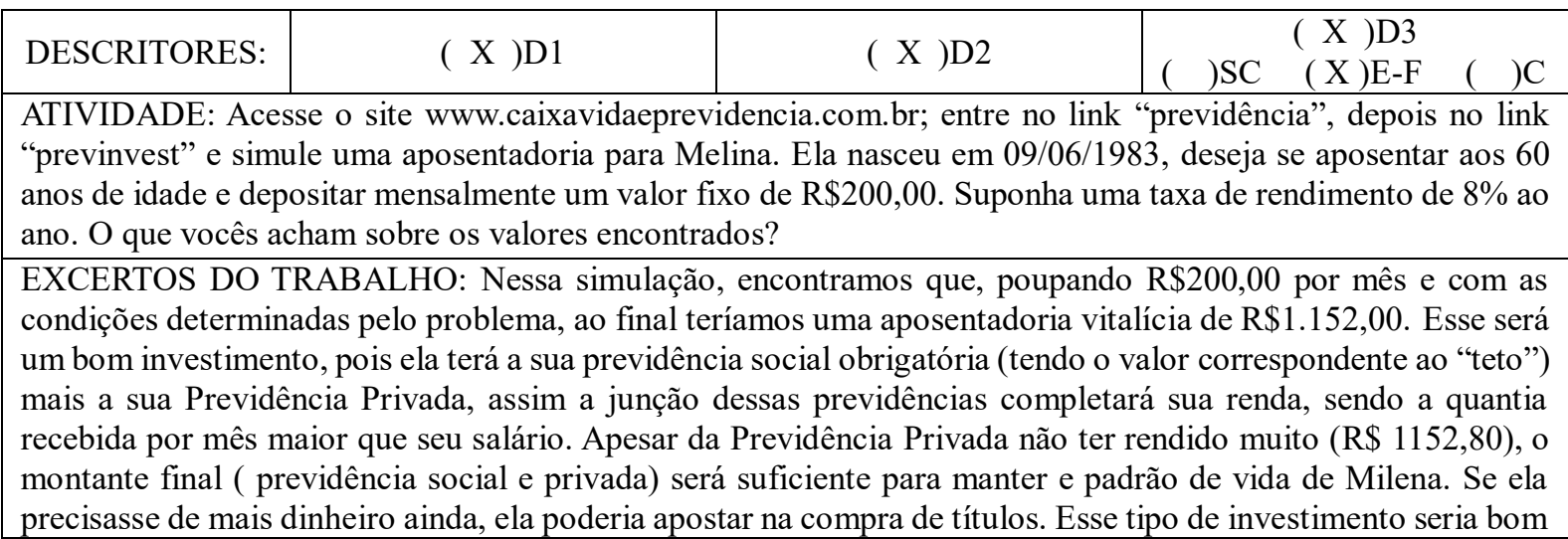


para uma pessoa mais nova, fazendo assim um investimento a longo prazo. No caso de Melina, seria paga uma grande taxa de juros, não valendo a pena esse tipo de investimento (SOUSA, 2012, p. 106-107).

Quadro 2 - Análise de atividade didática de Sousa (2012)

Fonte: Os autores (2021), a partir de Sousa (2012)

A questão, ao refletir sobre a aplicação de valores para a aposentadoria, enquadra-se no D1, pois considera-se pertinente tais reflexões com estudantes do Ensino Médio, em que muitos podem já estar no mercado de trabalho ou pretendem ingressar logo após a conclusão dos estudos da Educação Básica. Embora a pesquisa de Sousa tenha sido concluída em 2012, a atividade pode gerar diversos questionamentos na atualidade devido à aprovação da reforma da previdência e ao aumento da oferta de planos de previdência privados no Brasil.

Ademais, foi enquadrada no D2 devido aos estudantes terem divergido quanto ao Plano de Previdência Privada indicado e questionaram-se sobre os resultados encontrados. Pela análise dos argumentos presentes nos três excertos de discussões realizadas, observou-se que os estudantes consideraram aspectos econômicos e financeiros, como o montante final e a taxa de juros, além de aspectos abarcados em investimentos, como a proposta de compra de títulos. Outrossim, a questão de Sousa (2012) está alinhada às proposições da OCDE, devido a essa organização ter observado o aumento do número de pessoas que deveriam dar conta de suas aposentadorias, por meio de pensões e economias próprias.

Outra atividade (Quadro 3) que envolveu a aplicação de valores e rendimentos considerando uma taxa de juros fornecida, pertence ao estudo de Argôlo (2018).

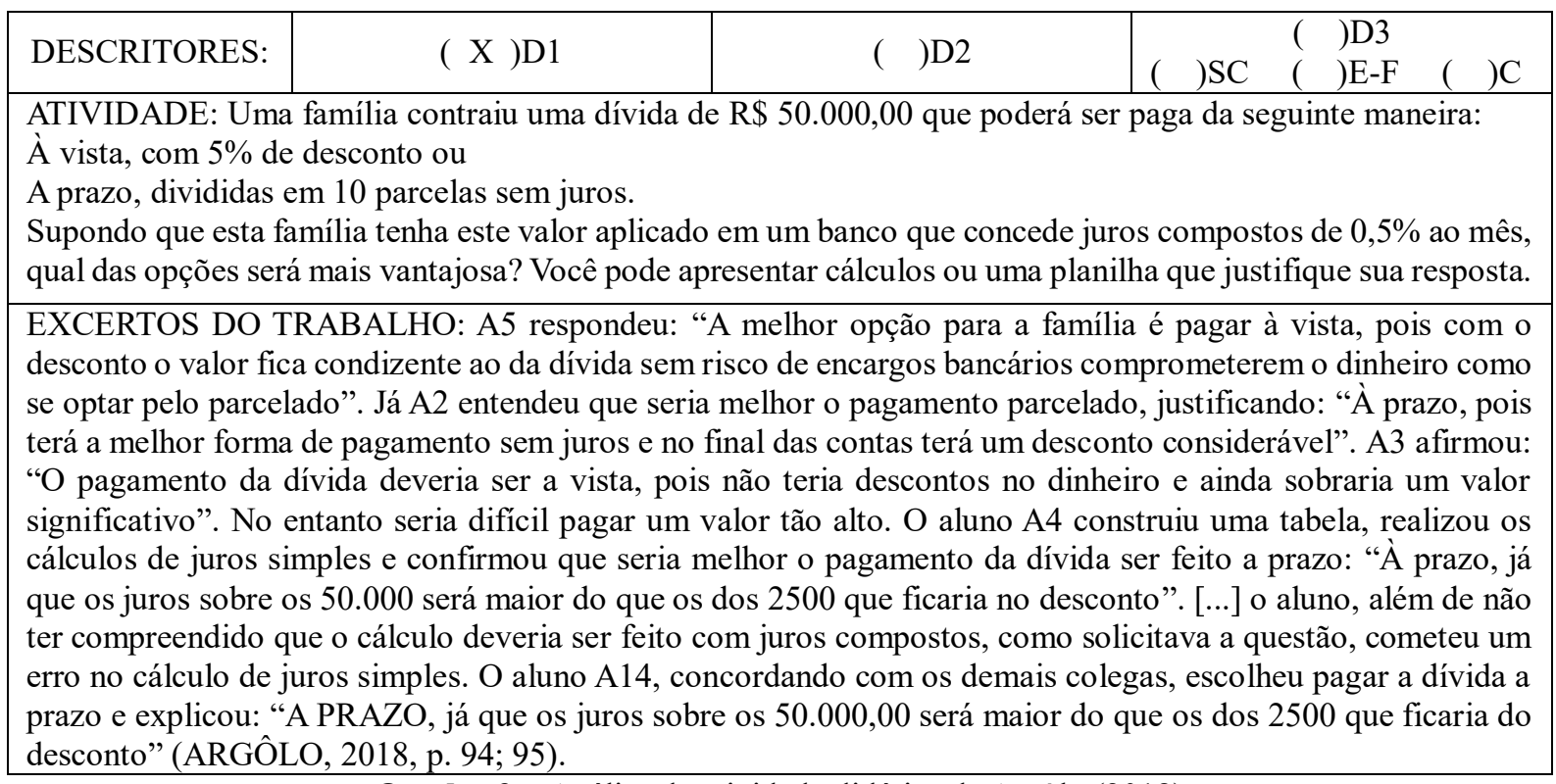

Quadro 3 - Análise de atividade didática de Argôlo (2018)

Fonte: Os autores (2021), a partir de Argôlo (2018)

A autora, mobilizada pela questão "Como o conhecimento da Educação Financeira pode fomentar a reflexão dos alunos do Ensino Médio e de suas famílias em relação ao planejamento 
financeiro?", dentre outros resultados, expôs que a sala de aula, saídas a campo e aulas no laboratório de informática, despertaram nos alunos, dentre outros aspectos, a autonomia e o senso crítico. Tal assertiva relaciona-se às ideias expostas por Muniz (2016), ao apontar diversos espaços que compõem os Ambientes de Educação Financeira Escolar.

Essa questão, ao propor que os estudantes analisassem se os juros ganhos na poupança seriam superiores ao valor do desconto no pagamento à vista, juntamente com os extratos da participação dos sujeitos, foi caracterizada no D1. Considera-se que a questão leva em conta apenas fatores matemáticos em sua pergunta norteadora, não permitindo aos estudantes tomarem decisão (D2) e considerarem aspectos nessa tomada (D3).

Além do exposto, a partir dos extratos do trabalho de Argôlo (2018), foi possível identificar equívocos nos cálculos realizados pelos estudantes, o que conduziu a escolhas distintas. Tal fato aponta a necessidade da correta utilização dos argumentos matemáticos mobilizados na tomada de decisão, conforme objetivo específico da Educação Financeira Escolar, apontado por Silva e Powell (2013).

Semelhante ao observado em Argôlo (2018), a atividade (Quadro 4) extraída de Leite (2018) foi enquadrada apenas no primeiro descritor. Essa pesquisa produziu um simulador financeiro educacional como aporte tecnológico à abordagem da Educação Financeira no ambiente escolar e, com base no experimento realizado com estudantes de $1^{\circ}$ ano do Ensino Médio, Leite (2018) apontou que o referido simulador auxiliou na observância de fatores econômicos e financeiros, como juros compostos e inflação de preços.

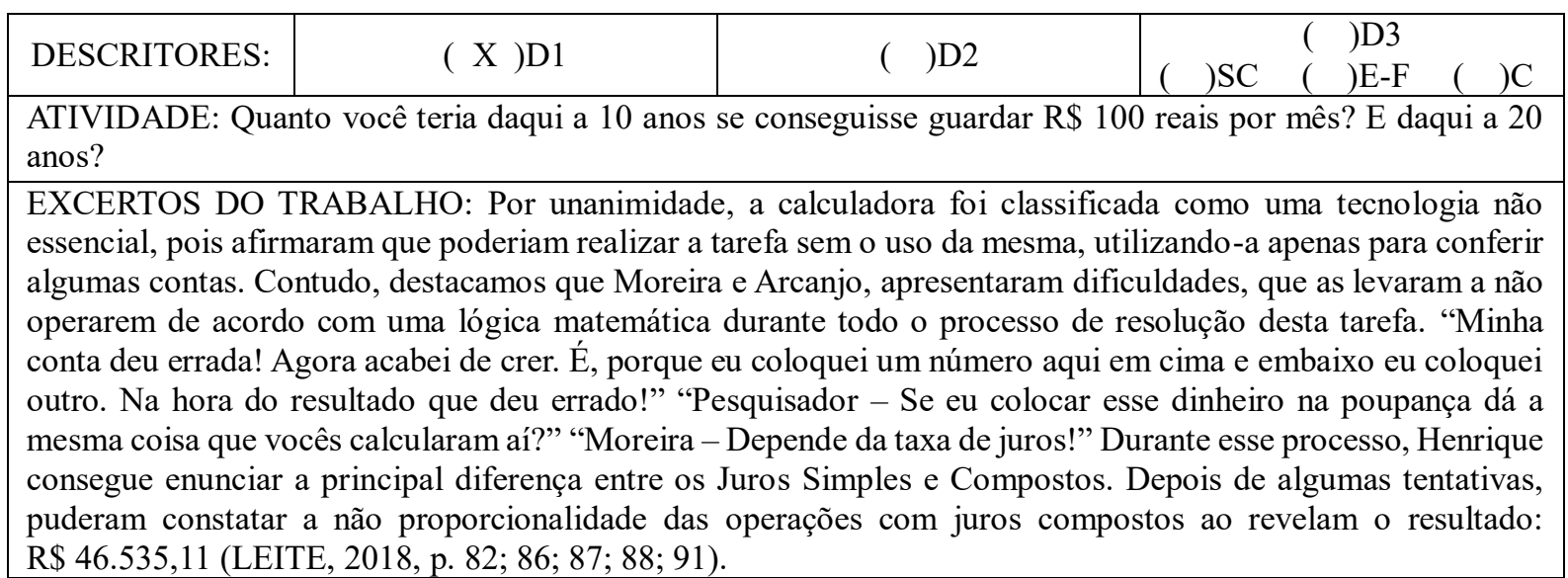

Quadro 4 - Análise de atividade didática de Leite (2018)

Fonte: Os autores (2021), a partir de Leite (2018)

Embora, muitas vezes, não seja realidade de estudantes de Ensino Médio a preocupação com poupar ou investir dinheiro, a classificação da atividade mencionada ocorreu pela observação de grande participação dos estudantes, em que alguns passaram a cogitar guardar dinheiro pensando no futuro. Outrossim, considera-se pertinente destacar que, apesar de estar 
classificada somente no D1, a atividade permitiu reflexões aos estudantes, a partir das propostas do pesquisador, discutindo-se aplicação de valor na poupança, utilização da HP 12C, juros compostos e sua relação com função exponencial.

Os excertos do trabalho de Leite (2018) permitem afirmar, dentre outros aspectos, que a atividade esteve alinhada com apontamentos da BNCC (BRASIL, 2018), os quais propõem a utilização de tecnologias, como a calculadora, e discussões relacionadas à Educação Financeira. A atividade também está relacionada aos eixos "noções básicas de finanças e economia", “finança pessoal e familiar" e "as oportunidades, os riscos e as armadilhas na gestão do dinheiro numa sociedade de consumo" apontados por Silva e Powell (2013), haja visto que discutem valor do dinheiro ao longo do tempo, oportunidades de investimentos, como a poupança, dentre outros aspectos.

O quarto estudo analisado foi o de Campos (2013), que explorou situações-problemas com estudantes do Ensino Médio, reforçando a necessidade de formar cidadãos críticos e conscientes financeiramente. A atividade (Quadro 5) permitiu aos estudantes refletirem sobre o uso do cartão de crédito.

\begin{tabular}{|c|c|c|c|}
\hline DESCRITORES: & ) 1 & $\mathrm{X}) \mathrm{D} 2$ & \\
\hline \multicolumn{4}{|c|}{$\begin{array}{l}\text { ATIVIDADE: Clara tem um cartão de crédito com limite de } \mathrm{R} \$ 500,00 \text {. Querendo muito presentear seu pai, } \\
\text { resolve comprar um relógio que custa exatos } \mathrm{R} \$ 500,00 \text {. Para essa compra ela decide efetuar o pagamento com } \\
\text { o cartão de crédito. No entanto, ao chegar a fatura do cartão, ela percebe que não tem o dinheiro para o } \\
\text { pagamento. Sabendo da possibilidade de parcelar a dívida do cartão de crédito em } 12 \text { x R } \$ 65,00 \text {, opta por essa } \\
\text { opção. O que você tem a dizer sobre a atitude de Clara? }\end{array}$} \\
\hline \multicolumn{4}{|c|}{$\begin{array}{l}\text { EXCERTOS DO TRABALHO: A situação de Clara revela que ela não terá o dinheiro para pagar a dívida, mas } \\
\text { se ela for dividir essa conta ela irá pagar R } \$ 280,00 \text { a mais, por isso não faria isso, pegaria o dinheiro que tenho } \\
\text { e pegaria o resto emprestado com alguém e pagaria a fatura. (Obs.: não pegaria emprestado com o banco). Como } \\
\text { Clara não tinha outra opção, era optar por parcelamento da dívida em } 12 \text { x } R \$ 65,00 \text {, pagando no total } R \$ 780,00 \text {. } \\
\text { Não considero uma boa escolha, pois parcelar dívida ou pagar valor mínimo só aumenta o tempo a pagar e o } \\
\text { valor da dívida. Clara não foi racional, pois deveria ter juntado o dinheiro para comprar o relógio, já que pagando } \\
\text { em parcelas de R } \$ 65,00 \text { por } 12 \text { meses, ela irá pagar R } \$ 280,00 \text { a mais do que o valor do relógio. Eu não agiria } \\
\text { da mesma forma que a Clara, pois prefiro comprar algo quando tenho o dinheiro. E se observarmos, duzentos e } \\
\text { oitenta reais foram pagos somente de juros. E com esse valor daria pra comprar um presente ainda melhor. } \\
\text { Assim, quando vemos Ana Clara dizer que não faria o empréstimo no banco, plausivelmente, parece-nos que } \\
\text { ela contraiu certa repulsa em relação aos bancos, uma espécie de bloqueio. Apesar de não concordarem com a } \\
\text { posição de Clara em optar pelo parcelamento do cartão de crédito, com exceção de Patrícia, nenhum dos alunos } \\
\text { constituiu objetos financeiro-econômicos para justificarem suas crenças-afirmações. Essa atividade, por sua } \\
\text { vez, possibilitou a discussão de formas alternativas para o pagamento das dívidas. Segundo os alunos, o mais } \\
\text { comum é recorrer a amigos e/ou parentes (CAMPOS, } 2013 \text {, p. } 142 ; 143 ; 144 \text { ). }\end{array}$} \\
\hline
\end{tabular}

Quadro 5 - Análise de atividade didática de Campos (2013)

Fonte: Os autores (2021), a partir de Campos (2013)

A partir dos extratos do trabalho, foi possível observar que os sujeitos da pesquisa se colocaram na situação de Clara (sujeito fictício da situação-problema), caracterizando D1. Sobre os argumentos da Tomada de Decisão (D2), foi possível identificar o aspecto sociocultural (D3 - SC) e comportamental (D3 - C), pois os estudantes apresentaram como possibilidades de pagamento: pedir ajuda a amigos e/ou parentes, negação ao empréstimo 
bancário e comparação entre o valor pago pelos juros e compra de um presente de melhor qualidade.

Os resultados presentes na atividade supracitada apontam para o desenvolvimento, por parte dos estudantes, do pensamento sobre riscos e armadilhas de questões financeiras, como objetiva a Educação Financeira Escolar (SILVA; POWELL, 2013). Também foi possível identificar semelhanças com proposições da OCDE e ENEF sobre a temática, por meio da conscientização sobre riscos e oportunidades financeiras.

A pesquisa desenvolvida por Sodré (2018, p. 9) objetivou "investigar como uma sequência didática pode contribuir para o ensino e a aprendizagem do conceito de juros compostos na formação em Educação Financeira de alunos do Ensino Médio”. Dentre as nove atividades divididas em dois blocos, duas apresentaram relações com o objetivo deste artigo, sendo que uma delas (Quadro 6) amparou-se em propostas da BNCC (BRASIL, 2018) quanto ao conceito de porcentagem.

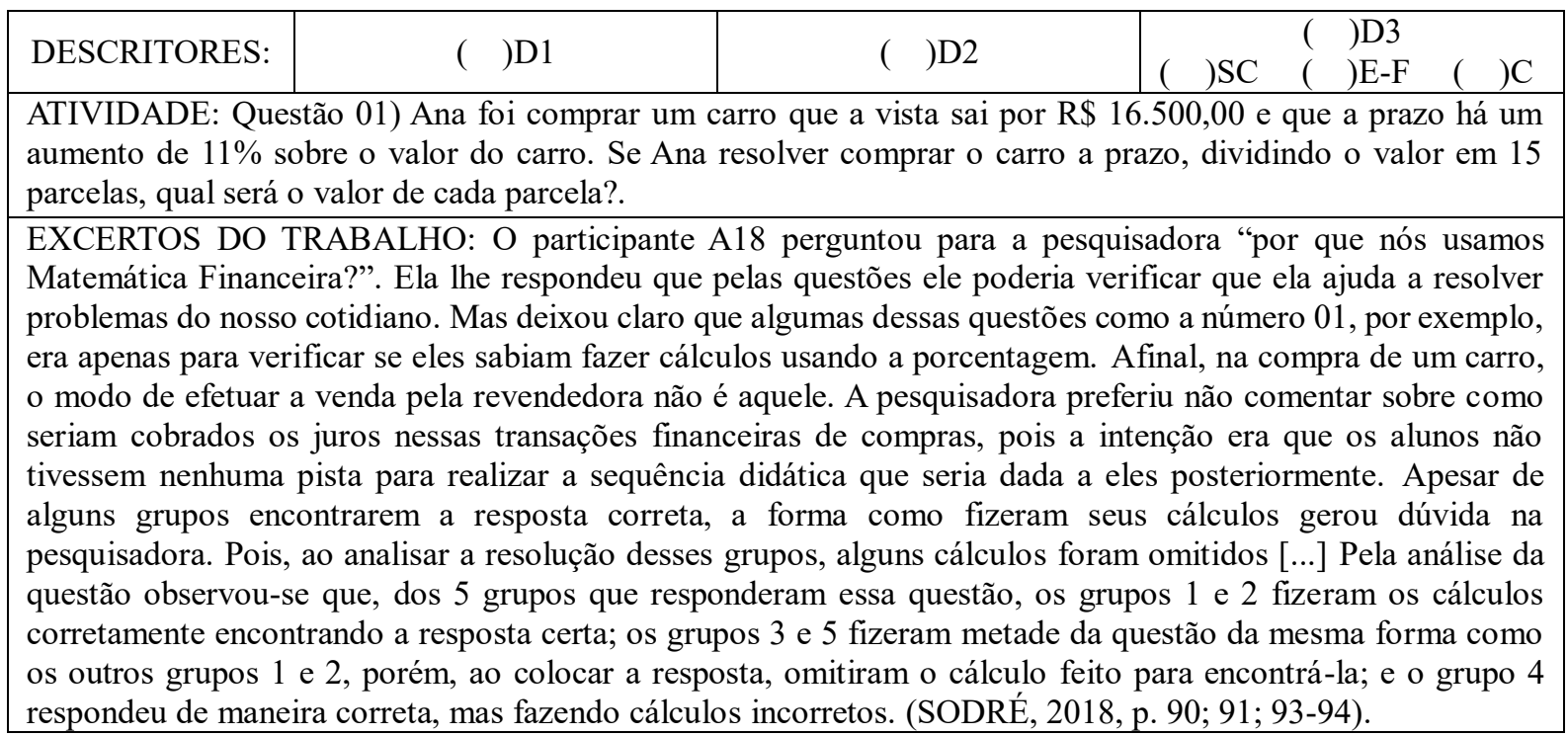

Quadro 6 - Análise de atividade didática de Sodré (2018)

Fonte: Os autores (2021), a partir de Sodré (2018)

A atividade apresentada por Sodré (2018), dentre as analisadas neste artigo, foi a única que não se enquadrou em nenhum dos descritores, fato considerado pelos próprios excertos do trabalho que apresentam que o objetivo da questão foi apenas verificar se os estudantes sabiam realizar cálculos de porcentagem e, em uma situação de compra de automóvel real, os juros serem calculados de maneira diferente ao previsto na atividade. Nesse sentido, contrapõem-se às proposições de Skovsmose (2000; 2001; 2007; 2014), que apresentam a importância de permitir estudos de conteúdos matemáticos associados a situações reais para os estudantes.

Compreende-se que essa atividade poderia despertar reflexões sobre a realidade do mercado financeiro, aliando a proposta ao estudo do conceito de progressões geométricas e 
séries periódicas uniformes. Apesar de não se enquadrar nos descritores, visualizam-se aspectos importantes, como sua proposta amparada na BNCC (BRASIL, 2018), conforme já mencionado, além de poder conscientizar estudantes para o uso correto de conhecimentos matemáticos da Educação Básica, conforme ideias de Silva e Powell (2013) sobre a Educação Financeira Escolar, como observado na atividade de Argôlo (2018).

A última atividade analisada foi extraída da pesquisa de Silva (2017b). Esse estudo esteve centrado em reflexões sobre riscos e armadilhas que estão presentes no comércio, visando o estímulo do consumo. A autora elaborou nove tarefas, presentes no produto educacional da dissertação, para auxiliar professores atuantes na Educação Básica.

A atividade encontrada (Quadro 7) foi caracterizada no D1, principalmente, por apresentar formas de pagamento semelhantes às do mercado brasileiro. Por sua vez, o D2 foi considerado diante das perguntas presentes na questão, indagando os estudantes a apresentarem justificativas sobre a análise dos itens, o que permitiu aos sujeitos envolvidos apresentar seus argumentos (D3).

\begin{tabular}{|l|l|l|l|}
\hline DESCRITORES: & $(\mathrm{X}) \mathrm{D} 1$ & $(\mathrm{X}) \mathrm{D} 2$ & $(\mathrm{X}) \mathrm{D} 3$ \\
\hline
\end{tabular}

ATIVIDADE: Gustavo e Mariana gostaram de um mesmo modelo de moto, no valor de R \$12.000,00. Ambos tinham esse valor em dinheiro para a aquisição da moto. Gustavo comprou a moto na Loja A, na qual foi oferecido, pelo vendedor, duas opções de pagamento: $10 \%$ de desconto para pagamento à vista ou 12 vezes de $\mathrm{R} \$ 1.000,00$ (sem juros). Já Mariana acabou comprando na Loja B, na qual o vendedor ofereceu também duas opções de pagamento: 5\% de desconto para pagamento à vista ou 24 vezes de R $\$ 500,00$ (sem juros). Agora responda:

a) Fazendo as contas, Gustavo deveria comprar à vista ou a prazo? Por que essa seria a melhor escolha?

b) Fazendo as contas, Mariana deveria comprar à vista ou a prazo? Por que essa seria a melhor escolha?

c) Nas duas lojas é dito "sem juros" para o pagamento parcelado. Você concorda com essa afirmação? Justifique sua resposta.

d) Em que condições a melhor forma de pagamento na compra de um produto é à vista? E a prazo?

EXCERTOS DO TRABALHO: A nona tarefa (vide p. 67) tem o objetivo de ressaltar a importância de analisar para tomada de decisão, observando qual pagamento seria mais vantajoso numa compra de um determinado produto, com condições à vista ou a prazo. Laura: E também, se você parar para pensar, ele tem 10\% de desconto se ele pagar à vista. Se ele for pagar de doze vezes, ele vai pagar o valor normal, sem o desconto, nem nada. Então vale mais à pena pagar à vista. Diana: E acaba que esses juros, esses $10 \%$ se transformam em juros. E outra coisa também que eu penso: todo pagamento à vista deveria ter um desconto, porque quando você paga no cartão, uma porcentagem é da empresa. Então não tem por que você pagar à vista e não ter esse desconto. Porque a pessoa, o vendedor, ele está ganhando ali em cima do produto tanto no valor que ele te vende, quanto nessa porcentagem que seria para a empresa que ele pegou para ele. É só isso. O pagamento à vista também seria a melhor escolha na situação da letra B, devido o ganho do desconto, ressaltado pelos sujeitos de pesquisa, mesmo o desconto sendo menor. Para elas a obtenção de descontos já se torna vantagem. Apesar das duas concordarem, em suas falas, que o valor dos descontos dados no pagamento à vista se tornam juros na compra a prazo, Laura ainda relata que depende de como se olha, já que não há efetivamente um aumento no valor real da moto na compra a prazo, respondendo então, em sua escrita, que concorda com o termo "sem juros". Eu coloquei que a melhor forma de pagamento à vista é quando se tem o desconto e a prazo é quando você consegue dividir de mais vezes, dependendo da sua situação. Interessante na fala de Diana, é que ela diz que as melhores condições para pagamento à vista e a prazo depende sempre da situação financeira do comprador, ou seja, quando se tem dinheiro para pagamento à vista só será conveniente se houver desconto, se não é melhor parcelar em mais vezes possível. Já Laura diz que se tiver desconto, melhor à vista e a prazo, se for sem juros (SILVA, 2017b, p. $117 ; 118 ; 119 ; 121)$.

Quadro 7 - Análise de atividade didática de Silva (2017b)

Fonte: Os autores (2021), a partir de Silva (2017b) 
Por meio dos excertos apresentados, observa-se que foram considerados aspectos econômicos e financeiros (D3 - E-F), principalmente pela porcentagem de desconto recebido à vista e, consequentemente, menor valor pago. Também pela crença de Diana que todo pagamento realizado à vista deveria ter um desconto, aponta-se que abarcou aspectos socioculturais (D3 - SC). Apesar de não ter sido encontrado um argumento que possibilitasse afirmar que as estudantes consideraram aspectos comportamentais, a atividade de Silva (2017b) foi a que esteve mais próxima de se enquadrar em todos os descritores sistematizados, fortemente pela abertura de respostas e questionamentos proporcionados pelos itens da questão.

Nesse sentido, torna-se importante destacar o papel docente na condução de tarefas no âmbito da Educação Financeira. A depender do professor, de suas experiências, conhecimentos e aprendizagens profissionais, abrem-se possibilidades didáticas para ampliar reflexões proporcionadas por um problema e, assim, contemplar todos os descritores sistematizados. A partir desse entendimento considera-se, ainda mais, a necessidade da inclusão da Educação Financeira na formação inicial e continuada de professores, principalmente de Matemática.

Com relação à aproximações e distanciamentos entre os temas das atividades analisadas, é possível salientar que três estiveram relacionadas à aplicação de dinheiro, discutindo aposentadoria e pagamento de dívidas, de acordo com eixos da Educação Financeira Escolar apontada por Silva e Powell (2013) e, também, que duas questões abordaram situação de compra de veículo e uma a utilização do cartão de crédito.

Dentre as seis atividades, cinco se enquadraram no D1, Interpretação do Contexto, sendo que duas delas revelaram somente esse descritor. Ademais, as questões que proporcionaram discussões sobre situações econômico-financeiras amparadas na Tomada de Decisão (D2), estão presentes em três atividades. Dentre as análises enquadradas em D2, enfatiza-se que os argumentos econômico-financeiros (D3 - E-F) e socioculturais (D3 - SC) foram os mais ponderados na tomada de decisão, fato que gera reflexões e indícios que questões relacionadas à emoção, paciência e heurísticas (D3 - C) são menos consideradas.

Por fim, apresentam-se apontamentos pertinentes presentes nas pesquisas em que as atividades foram extraídas para apreciação analítica, os quais convergem com perspectivas de intervenções escolares no âmbito da Educação Financeira, defendidas pelos autores deste artigo. Nesse sentido, Sousa (2012, p. 135) afirmou que os estudantes se colocaram "pessoalmente nas situações, exteriorizando casos particulares, mudando discursos e ideias defendidas a priori”. Já o tratamento da Educação Financeira “a partir de uma transversalidade interna ao currículo de Matemática" foi apontado por Campos (2013, p. 167). Em outra ótica, o simulador educacional financeiro pode "contribuir para um processo de tomada de decisão 
financeira, melhor fundamentado", podendo ser utilizado por professores em sua prática (LEITE, 2018, p. 130).

Em Sodré (2018, p. 168), os estudantes tiveram "liberdade de expressar diversas opiniões e conhecimentos" criando-se um ambiente dialógico na relação professor-aluno. A proposta desenvolvida por Argôlo (2018, p. 122) contribui "para a construção da criticidade, autonomia e reflexão dos sujeitos participantes da pesquisa". Ademais, considera-se que atividades de Educação Financeira permitam que os estudantes se identifiquem "com situações apresentadas, tendo estórias pessoais e familiares para contar" (SILVA, 2017b, p. 128).

\section{Considerações finais}

O presente artigo teve como principal objetivo identificar e analisar atividades didáticas desenvolvidas no Ensino Médio, que podem envolver tomada de decisão em situações econômico-financeiras relacionadas a séries periódicas uniformes, no âmbito da Educação Financeira e Educação Matemática Crítica. Com base em uma minuciosa seleção de corpus analítico, a partir de dissertações e teses mapeadas no Catálogo de Teses e Dissertações da Capes, foram analisadas seis atividades didáticas relacionadas aos objetivos deste artigo.

Dentre as análises, destaca-se que cinco questões permitiram aos estudantes identificarem um contexto coeso e coerente, o qual é de suma importância para refletir sobre a Educação Financeira no ambiente escolar. Entende-se que discussões relacionadas a essa temática devem levar em questão aspectos geográficos e socioeconômicos das escolas, podendo diferenciar formas de abordagem de atividades em todo país.

Ademais, dispõe-se que as atividades precisam, além de permitirem reflexões sobre o contexto que é necessário para se estudar a Educação Financeira por meio dos apontamentos dos referenciais sobre o assunto e sobre a Educação Financeira Escolar, gerar reflexões sobre a tomada de decisão amparada em argumentos não-matemáticos, sejam econômico-financeiros, socioculturais ou comportamentais (D3).

Assim, defende-se que atividades didáticas no âmbito da Educação Financeira devam inserir estudantes numa realidade que faz parte de sua vivência, convidando-os a perceber a importância dessa temática e dos conhecimentos matemáticos para amparar escolhas econômico-financeiras. À medida que atividades se enquadrarem nos três descritores sistematizados: Interpretação do Contexto (D1), Tomada de Decisão (D2) e Argumento na Tomada de Decisão (D3), entende-se que corroboram com a aprendizagem de novos conteúdos matemáticos e, sobretudo, de aspectos relacionados à construção da cidadania. 
Mesmo que não tenham sido identificados todos os descritores, depreende-se que, no desenvolvimento das atividades, alguns aspectos, não presentes nas dissertações analisadas, tornariam isso possível. Além disso, em uma perspectiva mais ampla, os contextos de sala de aula, as discussões e os encaminhamentos didáticos podem abarcar outros descritores.

Em relação à Educação Matemática, evidencia-se a importância do desenvolvimento de tarefas no ambiente escolar, discutindo conteúdos matemáticos previstos no currículo, principalmente o de progressões geométricas, aliados a reflexões no âmbito da Educação Financeira. É oportuno sobrelevar que existem limitações para pôr em prática esse apontamento, sendo necessário investimentos em formação continuada de docentes da Educação Básica, encorajando-os a trabalhar com a temática referida articulada às proposições da Base Nacional Comum Curricular. Também, destaca-se que essa proposta vai ao encontro de apontamentos que defendem a inserção da Educação Financeira de forma transversal.

Outrossim, a partir das observações realizadas ao final da seção anterior, por meio das pesquisas analisadas, conclui-se que estudos e propostas na visão da Educação Matemática, devem atentar a atividades didáticas que proporcionem aos estudantes, sejam da Educação Básica ou Ensino Superior, uma liberdade de expressão de ideias, sentimentos, conhecimentos e criticidade, corroborando com a construção de uma sociedade democrática, sendo a Educação Financeira uma das temáticas capaz de cumprir com essas questões.

Assim, considera-se pertinente novas pesquisas e práticas docentes que, ao abordarem progressões geométricas no Ensino Médio, relacionem esse conceito ao de séries periódicas uniformes. Tal fato pode direcionar esforços para ampliação da abordagem de tópicos de Educação Financeira nas escolas, assegurando aos estudantes a exploração de conhecimentos matemáticos, de modo argumentativo pautado em discussões não-matemáticas, tomando ciência para o posicionamento crítico de aspectos sociais e econômicos.

\section{Referências}

ARAÚJO-JORGE, T. C.; SOVIERZOSKI, H. H.; BORBA, M. C. A Área de Ensino após a avaliação quadrienal da CAPES: reflexões fora da caixa, inovações e desafios em 2017. Revista Brasileira de Ensino de Ciência e Tecnologia, Curitiba, v. 10, n. 3, p. 1-15, dez. 2017. Disponível em: https://periodicos.utfpr.edu.br/rbect/article/view/7744. Acesso em: 23 jul. 2020.

ARGÔLO, P. S. de. Educação financeira na sala de aula: uma proposta metodológica para o ensino da matemática no ensino médio. 2018. Dissertação (Mestrado em Ensino de Ciências Exatas) Universidade do Vale do Taquari, Lajeado, 2018.

BARDIN, L. Análise de conteúdo. $1^{\text {a }}$ ed. $3^{\text {a }}$ reimp. São Paulo: Edições 70, 2016. 
BARONI, A. K. C.; SILVA, E. C. da; MALTEMPI, M. V.; JAVARONI, S. L. Educação financeira e as contribuições do pensamento computacional em uma proposta de atividade voltada à tomada de decisão. Revista Brasileira de Educação em Ciências e Educação Matemática, Cascavel, v. 3, n. 2, p. 151-179, ago. 2019. Disponível em: http://erevista.unioeste.br/index.php/rebecem/article/view/22627. Acesso em: 07 out. 2020.

BORBA, M. C.; ARAUjO, J. L. (Org). Pesquisa Qualitativa em Educação Matemática. Belo Horizonte: Autêntica, 2004.

BRASIL. Decreto $\mathbf{n}^{0} \mathbf{7 . 3 9 7}$, de 22 de dezembro de 2010. Institui a Estratégia Nacional de Educação Financeira - ENEF. Brasília, DF, 2010. Disponível em: http://www.planalto.gov.br/ccivil_03/_Ato2007-2010/2010/Decreto/D7397.htm. Acesso em: 05 mai. 2020.

BRASIL. Ministério da Educação. Base Nacional Comum Curricular: educação é a base. Brasília: MEC, 2018. Disponível em:

http://basenacionalcomum.mec.gov.br/images/BNCC_EI_EF_110518_versaofinal_site.pdf. Acesso em: 23 out. 2020.

CAMPOS, A. B. Investigando como a educação financeira crítica pode contribuir na tomada de decisões de consumo de jovens-indivíduos-consumidores (JIC'S). 2013. Dissertação (Mestrado Profissional em Educação Matemática) - Universidade Federal de Juiz de Fora, Juiz de Fora, 2013.

CIRANI, C. B. S.; CAMPANARIO, M. A.; SILVA, H. H. M. A evolução do ensino da pós-graduação senso estrito no Brasil: análise exploratória e proposições para pesquisa. Avaliação, Campinas, v. 20, n. 1, p. 163-187, mar. 2015. Disponível em: https://www.scielo.br/pdf/aval/v20n1/1414-4077-aval-2001-00163.pdf. Acesso em: 17 jun. 2020.

CUNHA, C. L. da. Educação Financeira: uma perspectiva da disciplina Matemática no Ensino Médio pela Resolução de Problemas. 2014. Dissertação (Mestrado em Ensino de Ciências e Matemática) - Pontifícia Universidade Católica de Minas Gerais, Belo Horizonte, 2014.

CUNHA, C. L. da; LAUDARES, J. B. Resolução de Problemas na Matemática Financeira para Tratamento de Questões da Educação Financeira no Ensino Médio. Bolema, Rio Claro, v.31, n.58, p. 659-678, ago. 2017. Disponível em: https://www.scielo.br/scielo.php?script=sci_arttext\&pid=S0103636X2017000200659. Acesso em: 20 jun. 2020.

FIORENTINI, D.; LORENZATO, S. Investigação em educação matemática: percursos teóricos e metodológicos. Campinas: Autores Associados, 2006.

HARMUCH, D. Tarefas para uma educação financeira: um estudo. 2017. Dissertação (Mestrado Profissional em Ensino de Matemática) - Universidade Federal Tecnológica do Paraná, Londrina, 2017.

HARTMANN, A. L. B. Educação Financeira em Pesquisas Stricto Sensu no Brasil: um levantamento bibliográfico com foco na Tomada de Decisão. 2019. Trabalho de Conclusão de Curso (Graduação em Licenciatura em Matemática) - Universidade Federal de Santa Maria, Santa Maria, 2019.

HARTMANN, A. L. B; REISDOERFER, C; FERREIRA; I. F.; MARIANI, R. C. P. Educação Financeira No Ensino Médio: uma Experiência Sob o Olhar da Matemática Crítica. Jornal Internacional de Estudos em Educação Matemática, São Paulo, v. 12, n. 2, p. 154-163, set. 2019. Disponível em: https://revista.pgsskroton.com/index.php/jieem/article/view/6207. Acesso em: 05 mai. 2020. 
HOFMANN, R. M.; MORO, M. L. F. Educação matemática e educação financeira: perspectivas para a ENEF. Zetetike, Campinas, v. 20, n. 2, p. 37-54, mai. 2013.

LEITE, A. M. Produção e implementação de um simulador financeiro como aporte a tarefas destinadas ao ensino de Educação Financeira Escolar. 2018. Dissertação (Mestrado Profissional em Educação Matemática) - Universidade Federal de Juiz de Fora, Juiz de Fora, 2018.

MUNIZ, I. Jr. Econs Ou Humanos? Um Estudo Sobre a Tomada de decisão em Ambientes de Educação Financeira Escolar. 2016. Tese (Doutorado em Engenharia de Produção) - Universidade Federal do Rio de Janeiro, Rio de Janeiro, 2016.

MUNIZ, I. Jr; JURKIEWICZ, S. Tomada de Decisão e Trocas Intertemporais: uma contribuição para a construção de Ambientes de Educação Financeira Escolar nas aulas de matemática. Revista de Educação, Ciências e Matemática, Duque de Caxias, v. 6, n. 2, p. 76-99, set/dez. 2016. Disponível em: http://publicacoes.unigranrio.edu.br/index.php/recm/article/view/4071. Acesso em: 05 mai. 2020.

OCDE. Recommendation on Principles and Good Practices for Financial Education and Awareness. Directorade for Financial and Enterprice Affairs. 2005. Disponível em: http://www.oecd.org/finance/financial-education/35108560.pdf. Acesso em: 05 mai. 2020.

RASCHEN, S. R. Investigação sobre as contribuições da Matemática para o desenvolvimento da Educação Financeira na escola. 2016. Dissertação (Mestrado em Ensino de Matemática) Universidade Federal do Rio Grande do Sul, Porto Alegre, 2016.

ROCHA, A. J. C. Representações Semióticas Mobilizadas por Licenciandos em Matemática ao tomar decisões diante de situações econômico-financeiras. 2017. Dissertação (Mestrado em Educação Matemática) - Universidade Federal de Santa Maria, Santa Maria, 2017.

SILVA, A. M.; POWELL, A. B. Um programa de Educação Financeira para a Matemática Escolar da Educação Básica. In: ENCONTRO NACIONAL DE EDUCAÇÃO MATEMÁTICA, 11., 2013, Curitiba. Anais... Curitiba: Pontifícia Universidade Católica do Paraná, 2013. p. 1-17.

SILVA, A. M.; POWELL, A. B. Educação Financeira na Escola: A perspectiva da Organização para a Cooperação e Desenvolvimento Econômico. Boletim GEPEM, Seropédica, v. 66, p. 3-19, jan./jun.,2015.

SILVA, M. do C. P da. E-book Interativo: um olhar para a Educação Financeira na educação básica. 2017a. Dissertação (Mestrado profissional em Ensino Científico e Tecnológico) - Universidade Regional Integrada do Alto Uruguai e das Missões, Santo Ângelo, 2017.

SILVA, V. H. B. da C. Educação financeira escolar: os riscos e as armadilhas presentes no comércio, na sociedade de consumidores. 2017b. Dissertação (Mestrado Profissional em Educação Matemática) - Universidade Federal de Juiz de Fora, Juiz de Fora, 2017.

SKOVSMOSE, O. Cenários para a investigação. Bolema, Rio Claro, v. 13, n. 14, p. 66- 91, set. 2000.

SKOVSMOSE, O. Educação Matemática Crítica: a questão da democracia. Campinas: Papirus, 2001.

SKOVSMOSE, O. Educação Crítica: incerteza, matemática, responsabilidade. Tradução de Maria Aparecida Viggiani Bicudo. São Paulo: Cortez, 2007.

SKOVSMOSE, O. Um convite à educação matemática crítica. Tradução de Orlando de Andrade Figueiredo. 1 reimp. Campinas: Papirus, 2014. 
SODRÉ, A. A. S. L. Investigando uma sequência didática sobre juros compostos para a formação em educação financeira de alunos do ensino médio. 2018. Dissertação (Mestrado Profissional em Educação Matemática) - Universidade Federal de Ouro Preto, Ouro Preto, 2018.

SOUSA, L de. Resolução de problemas e simulações: investigando potencialidades e limites de uma proposta de Educação Financeira para alunos do Ensino Médio de uma escola da rede privada de Belo Horizonte (MG). 2012. Dissertação (Mestrado Profissional em Educação Matemática) - Universidade Federal de Ouro Preto, Ouro Preto, 2012.

TREVISAN, A. R. Educação financeira: uma proposta interdisciplinar de trabalho com o ensino médio. 2018. Dissertação (Mestrado em Processos de Ensino, Gestão e Inovação) - Universidade de Araraquara, Araraquara, 2018.

VILLA, L. Educação financeira no ensino médio: uma análise a partir da aprendizagem significativa de David Ausubel. 2017. Dissertação (Mestrado em Ensino de Ciências e Matemática) - Universidade de Passo Fundo, Passo Fundo, 2017.

YIN, R. K. Pesquisa Qualitativa do Início ao Fim: Série Métodos de Pesquisa. Porto Alegre: Penso, 2016.

Submetido em 25 de Outubro de 2020. Aprovado em 21 de Janeiro de 2021. 